\title{
Inhibition of H1N1 influenza virus infection by zinc oxide nanoparticles: another emerging application of nanomedicine
}

\author{
Hadi Ghaffari ${ }^{1}$, Ahmad Tavakoli', Abdolvahab Moradi ${ }^{2}$, Alijan Tabarraei², Farah Bokharaei-Salim', \\ Masoumeh Zahmatkeshan ${ }^{3,4}$, Mohammad Farahmand ${ }^{5}$, Davod Javanmard ${ }^{1}$, Seyed Jalal Kiani ${ }^{1}$, Maryam Esghaei ${ }^{1}$, \\ Vahid Pirhajati-Mahabadi ${ }^{3,6}$, Seyed Hamidreza Monavari ${ }^{1 *}$ and Angila Ataei-Pirkooh ${ }^{1 *}$
}

\begin{abstract}
Background: Currently available anti-influenza drugs are often associated with limitations such as toxicity and the appearance of drug-resistant strains. Therefore, there is a pressing need for the development of novel, safe and more efficient antiviral agents. In this study, we evaluated the antiviral activity of zinc oxide nanoparticles (ZnO-NPs) and PEGylated zinc oxide nanoparticles against H1N1 influenza virus.

Methods: The nanoparticles were characterized using the inductively coupled plasma mass spectrometry, $x$-ray diffraction analysis, and electron microscopy. MTT assay was applied to assess the cytotoxicity of the nanoparticles, and anti-influenza activity was determined by TCID50 and quantitative Real-Time PCR assays. To study the inhibitory impact of nanoparticles on the expression of viral antigens, an indirect immunofluorescence assay was also performed.

Results: Post-exposure of influenza virus with PEGylated ZnO-NPs and bare ZnO-NPs at the highest non-toxic concentrations could be led to 2.8 and $1.2 \log 10$ TCID50 reduction in virus titer when compared to the virus control, respectively $(P<0.0001)$. At the highest non-toxic concentrations, the PEGylated and unPEGylated ZnO-NPs led to inhibition rates of $94.6 \%$ and $52.2 \%$, respectively, which were calculated based on the viral loads. There was a substantial decrease in fluorescence emission intensity in viral-infected cell treated with PEGylated ZnO-NPs compared to the positive control.
\end{abstract}

Conclusions: Taken together, our study indicated that PEGylated ZnO-NPs could be a novel, effective, and promising antiviral agent against $\mathrm{H} 1 \mathrm{~N} 1$ influenza virus infection, and future studies can be designed to explore the exact antiviral mechanism of these nanoparticles.

Keywords: Antiviral activity, Zinc oxide nanoparticle, H1N1 influenza, Polyethylene glycol

\section{Background}

Influenza viruses are important human respiratory tract pathogens responsible for the seasonal epidemics and sporadic pandemics around the world [1]. According to the recent estimates reported by the World Health Organization (WHO), seasonal influenza epidemics lead to about 3-5 million cases of severe illness and approximately 290.000 to 650.000 deaths annually worldwide [2]. Influenza viruses are classified as type A, B, C and D

\footnotetext{
* Correspondence: Monavari.hr@iums.ac.ir; Ataei.a@iums.ac.ir

'Department of Medical Virology, Iran University of Medical Sciences, Tehran, Iran

Full list of author information is available at the end of the article
}

on the basis of antigenicity of the viral nucleoprotein and major matrix protein, of which only influenza $\mathrm{A}$ and $B$ viruses are the major culprit in human disease [3-6].

Presently, there are only two classes of drugs available against different influenza A strains and subtypes licensed by the U.S. Food and Drug Administration (FDA): matrix-2 (M2) protein ion channel blockers (such as amantadine and rimantadine) and neuraminidase (NA) inhibitors (such as zanamivir and oseltamivir) [7]. However, during the last years, there has been a remarkable increase in the emergence of drug-resistant strains, which have become a major public health concern around the world $[8,9]$. Therefore, there is a growing

(c) The Author(s). 2019 Open Access This article is distributed under the terms of the Creative Commons Attribution 4.0 International License (http://creativecommons.org/licenses/by/4.0/), which permits unrestricted use, distribution, and 
need to identify and evaluate alternative anti-influenza agents which exert a different mechanism of action compared with the conventional drugs.

Recent advancements in nanotechnology have provided unique opportunities in the field of drug development programs. Nanoparticles are known as major products of the nanotechnologies with at least one dimension of $100 \mathrm{~nm}$ or less, and have attracted great interest due to their intriguing and unique properties compared to their bulk material $[10,11]$. These characteristics make them suitable for different biomedical applications such as drug delivery, medical diagnostics and therapeutics [12]. Different biological and antimicrobial properties can also be achieved by surface modifications of nanoparticles [13].

During the last years, metal nanoparticles have been shown to be efficient against a wide range of pathogens including bacteria, fungi, parasites and viruses [14]. Among metal nanoparticles, zinc oxide nanoparticles (ZnO-NPs) have been demonstrated to exert antimicrobial activities against various human pathogens [15]. However, most studies have focused on their inhibitory actions on bacterial infections, and there is limited studies evaluating the interaction between $\mathrm{ZnO}-\mathrm{NPs}$ and viruses. In a recent work by our group, we found a strong inhibitory effects of $\mathrm{ZnO}-\mathrm{NPs}$ and polyethylene glycol (PEG)-coated ZnO-NPs (ZnO-PEG-NPs) on HSV-1 [16]. In this line, we have decided to conduct the current study to investigate the effects of $\mathrm{ZnO}-\mathrm{NPs}$ and $\mathrm{ZnO}$ PEG-NPs on the replication of H1N1 influenza virus, which are amongst the most challenging viruses that threaten human health.

\section{Methods}

\section{Preparation and characterization of nanoparticles}

The powdered zinc oxide nanoparticles were purchased from US Research Nanomaterials (USA; Product Number: US3590). Nanoparticles were suspended in Dulbecco's Modified Eagle's medium (DMEM) (Invitrogen, USA) and the suspension were subjected to sonication to prevent agglomeration and make different concentrations. Oseltamivir purchased from Sigma-Aldrich (St. Louis, MO, USA) were dissolved in DMEM and used as a standard drug against influenza at different concentrations. Polyethylene glycol (PEG) 6000 was also purchased from SigmaAldrich. PEGylated $\mathrm{ZnO}-\mathrm{NPs}$ were synthesized by mechanical method, as described in detail previously [16]. Inductively coupled plasma mass spectrometry (ICP-MS), $\mathrm{X}$-ray diffraction analysis (XRD), Transmission Electron Microscopy (TEM), and Field Emission Scanning Electron Microscope (FE-SEM) were used for characterization of nanoparticles. Thermogravimetric analysis (TGA) was also performed to demonstrate the presence of PEG on the surface of $\mathrm{ZnO}$ nanoparticles [16].
Cell culture and virus propagation

Madin-Darby canine kidney (MDCK)-SIAT1 cells were a gift from the Razi Vaccine and Serum Research Institute (Karaj, Iran). The cells were grown at $37^{\circ} \mathrm{C}$ in $5 \% \mathrm{CO} 2$ in DMEM, supplemented with $10 \%$ heat-inactivated fetal bovine serum (FBS; Invitrogen, USA), $1 \mathrm{mM}$ sodium pyruvate (Merck, Germany), 2 mM L-glutamine (Merck, Germany), and $100 \mathrm{U} / \mathrm{ml}$ penicillin and $100 \mu \mathrm{g} / \mathrm{ml}$ streptomycin sulfate (Sigma-Aldrich, USA).

Influenza A/Puerto Rico/8/34 (H1N1; PR8) was also obtained from the Razi Vaccine and Serum Research Institute, and propagated in MDCK-SIAT1 cells. For virus-stock preparation, MDCK-SIAT1 cell monolayer in $25-\mathrm{cm}^{2}$ flask (SPL Life Science, South Korea) was washed three times with phosphate-buffered saline (PBS, Bio-Idea, Iran), and the cells were infected with the virus at a multiplicity of infection (MOI) of 0.1 for $1 \mathrm{~h}$ at $35^{\circ} \mathrm{C}$. Afterwards, the virus inoculum was removed and the cells were overlaid with infection medium containing serum-free DMEM, $2 \mu \mathrm{g} / \mathrm{ml}$ trypsin-TPCK (Merck, Germany), 25 mM HEPES buffer (Sigma-Aldrich, USA), and $0.14 \%$ of bovine serum albumin (BSA; SigmaAldrich, USA), and the flask was then incubated at $35^{\circ} \mathrm{C}$ for an additional $48 \mathrm{~h}$. The virus-containing supernatants were harvested at $48 \mathrm{~h}$ post infection, clarified by centrifugation at $2500 \mathrm{rpm}$ for $10 \mathrm{~min}$ at $4^{\circ}$, and filtered by sterile syringe filter $0.22 \mu \mathrm{m}$ (Millipore, Ireland). The virus was then aliquoted into sterile cryovials and stored frozen at $-80^{\circ} \mathrm{C}$ until use. Virus was titrated using the tissue culture infectious dose 50 (TCID50) method according to the Reed and Muench formula [17], and was used for the next in vitro experiments at the titer of 100 $\mathrm{TCID} 50 / \mathrm{mL}$.

\section{Determination of cell viability}

The cytotoxicity of nanoparticles was assessed by MTT assay. Briefly, MDCK-SIAT1 cells at a density of $1 \times 10^{5}$ cells $/ \mathrm{mL}$ were seeded in a flat-bottomed 96 -well microtiter plate (SPL Life Science, South Korea), and were incubated for $24 \mathrm{~h}$ at $37^{\circ} \mathrm{C}$ and $5 \% \mathrm{CO}$. A range of concentrations from 25 to $225 \mu \mathrm{g} / \mathrm{ml}$ of nanoparticles was prepared using the cell culture medium and was added to the plate in triplicate. After $48 \mathrm{~h}$, the treatments were removed, and $10 \mu \mathrm{L}$ of MTT reagent and $100 \mu \mathrm{L}$ RPMI (Bio-Idea, Iran) were added to each well and incubated for a further $4 \mathrm{~h}$. The medium was then removed and $50 \mu \mathrm{L}$ of DMSO solution was added to the wells. Finally, the plate was read at $550 \mathrm{~nm}$ by a microplate reader (Hiperion MPR 4+, Germany).

\section{Assessment of antiviral activities Virucidal activity}

To evaluate direct effects of $\mathrm{ZnO}$ and $\mathrm{ZnO}-\mathrm{PEG}$ nanoparticles on $\mathrm{H} 1 \mathrm{~N} 1$ influenza particles, equal volumes of 
the viral suspensions (100 TCID50/ml) and nanoparticles suspensions in non-toxic concentration ranges were mixed and incubated at $37{ }^{\circ} \mathrm{C}$ for $4 \mathrm{~h}$ in a humidified $5 \%$ $\mathrm{CO} 2$ atmosphere. The mixture $(100 \mu \mathrm{L})$ was then added in triplicated wells of the confluent monolayer of MDCKSIAT1 cells $\left(2 \times 10^{4}\right.$ cells/well $)$ in a flat-bottomed 96-well microtiter plate and further incubated for $1 \mathrm{~h}$ at $35^{\circ} \mathrm{C}$. The virus control (infected but untreated) and cell control (uninfected untreated cells) were kept in each plate prepared throughout the experiment. After $1 \mathrm{~h}$ incubation, the mixture was discarded, and the cells were washed three times with PBS to remove non-absorbed viruses and overlaid with infection medium. The plate was then incubated for $48 \mathrm{~h}$ at $35^{\circ} \mathrm{C}$ in a humidified $5 \% \mathrm{CO} 2$ atmosphere.

\section{Pre-exposure antiviral activity}

The confluent monolayer of MDCK-SIAT1 cells $\left(2 \times 10^{4}\right.$ cells/well) in a flat-bottomed 96-well microtiter plate were pre-incubated with different concentrations of $\mathrm{ZnO}$ and $\mathrm{ZnO}-\mathrm{PEG}$ nanoparticles in non-toxic concentration ranges in triplicates for $3 \mathrm{~h}$ at $37^{\circ} \mathrm{C}$. The media containing nanoparticles was discarded from the wells, and the cells were washed three times with PBS and then incubated for $1 \mathrm{~h}$ at $35^{\circ} \mathrm{C}$ with 100 TCID50/mL virus. Afterwards, the virus inocula were removed from the wells, and the cells were washed three times with PBS, and were then overlaid with infection medium. The plate was further incubated for $48 \mathrm{~h}$ at $35^{\circ} \mathrm{C}$ in a humidified 5\% CO2 atmosphere. The virus and cell controls were kept as described above.

\section{Cell co-treatment assay}

The co-treatment assay was performed to evaluate the functions of nanoparticles in inhibiting viral binding. MDCK-SIAT1 cells were grown in a flat-bottomed 96well microtiter plate at the density of $2 \times 10^{4}$ cells/well. The media was removed from all wells and $100 \mu \mathrm{L}$ of nanoparticles suspensions at their non-toxic concentrations and $100 \mu \mathrm{L}$ of $100 \mathrm{TCID} 50 / \mathrm{mL}$ viral suspensions were added simultaneously to the cells in triplicated and incubated for $1 \mathrm{~h}$ at $35^{\circ} \mathrm{C}$. The virus and cell controls were also included in this assay. Following $1 \mathrm{~h}$ incubation, the solution on the cells was discarded and the cells were washed three times with PBS, and were overlaid with infection medium. The plate was incubated for an additional $48 \mathrm{~h}$ at $35^{\circ} \mathrm{C}$ with $5 \% \mathrm{CO}$.

\section{Post-exposure antiviral activity}

The confluent monolayer of MDCK-SIAT1 cells $\left(2 \times 10^{4}\right.$ cells/well) in all wells of a flat-bottomed 96-well microtiter plate were incubated with $100 \mu \mathrm{L}$ of $100 \mathrm{TCID} 50 / \mathrm{mL}$ $\mathrm{H} 1 \mathrm{~N} 1$ virus suspensions for $1 \mathrm{~h}$ at $35^{\circ} \mathrm{C}$ in a humidified $5 \% \mathrm{CO} 2$ incubator. The virus inocula were then discarded from the wells, and the cells were washed three times with PBS for removing unattached viruses. Different non-cytotoxic concentrations of $\mathrm{ZnO}$ and $\mathrm{ZnO}$-PEG nanoparticles suspended in infection medium were then added in triplicate to the wells and the plate further incubated for $48 \mathrm{~h}$ at $35{ }^{\circ} \mathrm{C}$ in a humidified $5 \% \mathrm{CO} 2$ atmosphere. The virus control (virus + DMEM) and the cell control (uninfected cells in DMEM) were also included in this experiment. This assay was also carried out for oseltamivir and soluble polyethylene glycol.

At the indicated time of all above experiments (at $48 \mathrm{~h}$ ), the supernatant of each well was harvested and was subjected to TCID50 and quantitative Real-Time PCR assays to determine the amount of total progeny virus.

\section{Quantitative Real-Time PCR assay}

To determine influenza viral load, a quantitative system using Real-Time PCR assay was carried out. Total RNA was extracted from the supernatants using the AccuPrep $^{\circ}$ Viral RNA Extraction Kit (Bioneer, South Korea), based on manufacturer's protocol. The extracted RNA was then subjected to reverse transcription using the cDNA Synthesis Kit (Roche Diagnostics, Germany), according to manufacturer's recommendations. Finally, quantitative Real-Time PCR was performed using the Genesig ${ }^{\circ}$ Advanced kit (PrimerDesign Ltd., United Kingdom), according to manufacturer's instructions. The kit contains primers and probe designed for detection of all influenza A subtypes. The assay was performed using the Rotor-Gene Q instrument (Qiagen, Germany) under the following conditions: 5 min activation of Taq DNA polymerase at $95^{\circ} \mathrm{C}$, followed by 40 cycles of 10 s at $95^{\circ} \mathrm{C}$ and $60 \mathrm{~s}$ at $60^{\circ} \mathrm{C}$.

\section{Indirect immunofluorescence assay (IFA)}

MDCK-SIAT1 cells $\left(5.0 \times 10^{4}\right)$ were seeded on sterile glass coverslips (Nunc, Denmark) in a 24-well plate and grown until $80-90 \%$ confluence. The media was discarded and the cells were incubated with $200 \mu \mathrm{L}$ of 100 TCID50/mL H1N1 virus suspensions for $1 \mathrm{~h}$ at $35^{\circ} \mathrm{C}$ in a humidified $5 \% \mathrm{CO} 2$ incubator. The virus inocula were then discarded from the wells, and the cells were washed three times with PBS. The maximum non-cytotoxic concentrations of nanoparticles (75 and $200 \mu \mathrm{g} / \mathrm{ml}$ of $\mathrm{ZnO}$ NPs and ZnO-PEG-NPs, respectively) suspended in serum-free DMEM supplemented with trypsin-TPCK, HEPES buffer, and BSA were then added to the wells and the plate was incubated at $35{ }^{\circ} \mathrm{C}$ with $5 \% \mathrm{CO}$. The virus and cell controls were also included in this experiment. After $24 \mathrm{~h}$, the cells were fixed with cold acetone $\left(4{ }^{\circ} \mathrm{C}\right)$ for $20 \mathrm{~min}$, and the fixed cells were overlaid with antiinfluenza A monoclonal antibody (Chemicon-Millipore, USA), followed by incubation at $37^{\circ} \mathrm{C}$ for $45 \mathrm{~min}$. In the next step, the cells were washed three time with PBS, and were then overlaid with fluorescein isothiocyanate (FITC)- 
conjugated mouse anti-human antibody (Dako, Germany), followed by incubation at $37^{\circ} \mathrm{C}$ for $30 \mathrm{~min}$. Afterwards, the cells were washed three time with PBS and coverslips were mounted in slides with glycerol buffer. Ultimately, the cells were visualized under the Olympus BH2-RFCA fluorescence microscope (Tokyo, Japan).

\section{Statistical analysis}

Values represent the mean of three independent experiments. The results were tabulated, and differences between means were statistically analyzed using one-way analysis of variance (ANOVA), followed by Tukey's multiple comparison test. All analyses were carried out using the GraphPad Prism software, version 7.0 (GraphPad Software, USA), and $P$ values less than 0.05 were taken as statistically significant.

\section{Results}

\section{Characterization of the nanoparticles}

The FE-SEM images of ZnO-NPs and ZnO-PEG-NPs are shown in Fig. 1. The average diameters of $\mathrm{ZnO}-\mathrm{NPs}$ ranged between 20 and $50 \mathrm{~nm}$, whereas the $\mathrm{ZnO}$-PEG-
NPs were ranged from 16 to $20 \mathrm{~nm}$. This reveals that PEGylation of ZnO-NPs by severe ball milling technique has led to a substantial decrease in the size of nanoparticles. The both nanoparticles were also spherical shaped and uniform. Surface coating of $\mathrm{ZnO}-\mathrm{NPs}$ was also observed in Fig. 1 (c).

Figure 2 indicates the XRD powder diffraction patterns of the $\mathrm{ZnO}-\mathrm{NPs}$. The position and relative intensities of all diffraction peaks are similar to the standard XRD pattern of $\mathrm{ZnO}[18,19]$.

In addition, ICP-MS measurement confirmed the high purity level of $\mathrm{ZnO}-\mathrm{NPs}$. The thermogravimetric analysis (TGA) of the ZnO-NPs and ZnO-PEG-NPs is presented in Fig. 3. The ZnO-PEG-NPs showed a significant weight loss of $32.22 \%$ at a temperature of $400{ }^{\circ} \mathrm{C}$, whereas the $\mathrm{ZnO}-\mathrm{NPs}$ showed a small weight loss of $3.6 \%$ at the same temperature. This corresponds to loss of polyethylene glycol, which was coated on the surface of ZnO-NPs.

\section{Cytotoxicity assay}

Cytotoxic effects of ZnO-NPs, ZnO-PEG-NPs, polyethylene glycol, and oseltamivir on MDCK-SIAT1 cells were

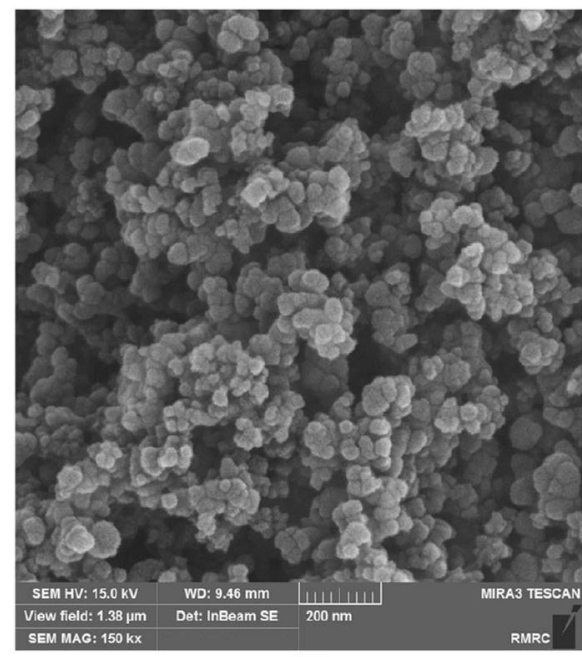

(a)

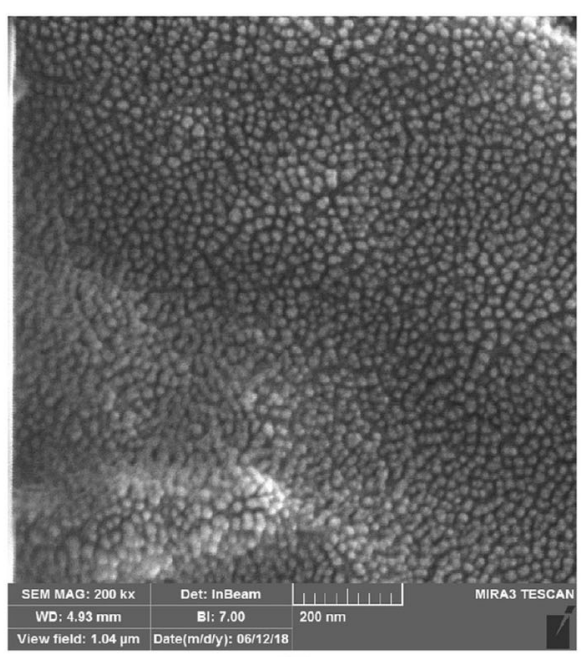

(b)

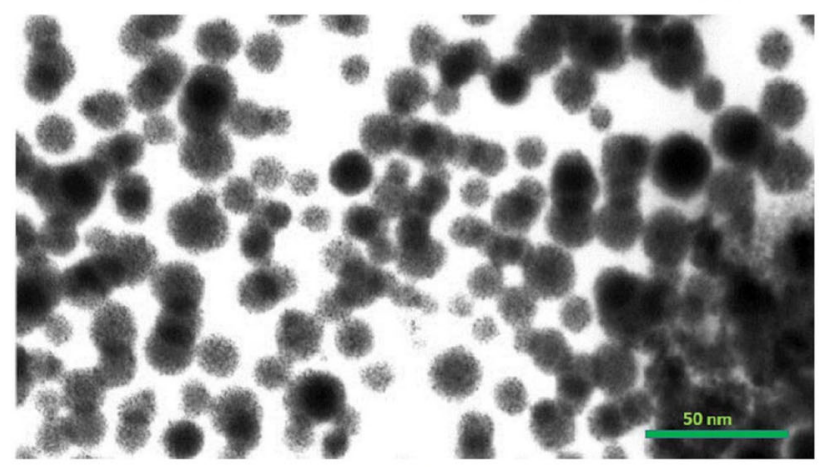

(c)

Fig. 1 FE-SEM images of ZnO-NPs (a) and ZnO-PEG-NPs (b); TEM image of ZnO-PEG-NPs (c) 


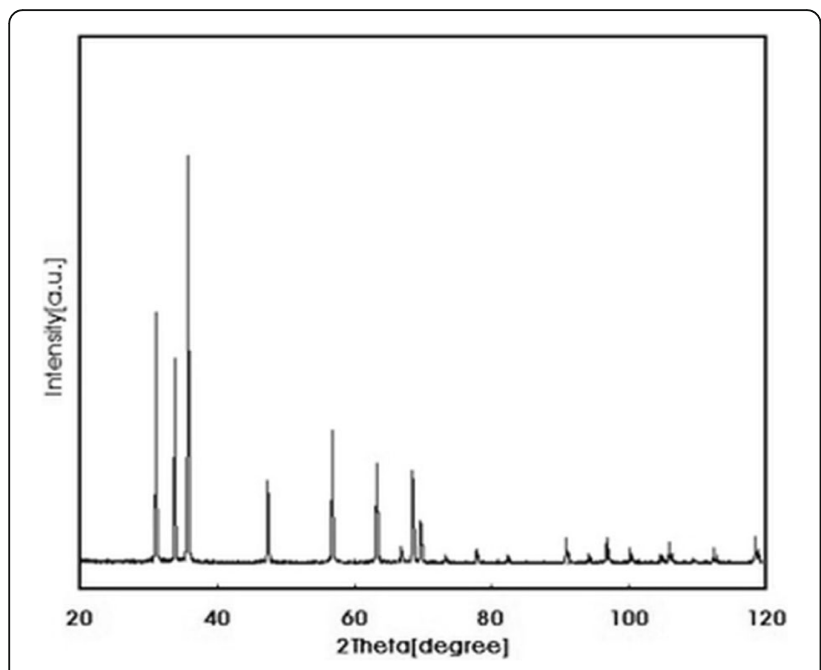

Fig. 2 Powder X-ray Diffraction Pattern of ZnO-NPs determined using the MTT assay. As shown in Fig. 4, polyethylene glycol and oseltamivir did not show significant cytotoxic effects toward MDCK-SIAT1 cells. The results obtained in the MTT assay revealed that the cytotoxicity of ZnO-PEG-NPs was significantly lower than that of $\mathrm{ZnO}-\mathrm{NPs}$, so that the viability was determined greater than $90 \%$ up to the concentration of 75 and $200 \mu \mathrm{g} / \mathrm{mL}$ of ZnO-NPs and ZnO-PEG-NPs, respectively.

\section{Assessment of antiviral activity}

The results of TCID50 assay showed that the pre- and co-exposure of cells to $\mathrm{ZnO}$-NPs and $\mathrm{ZnO}$-PEG-NPs did not lead to any reduction of the H1N1 influenza virus titer. Meanwhile, virucidal activity was not observed at any concentrations of nanoparticles, suggesting that nanoparticles could not act directly against the influenza virus particle resulting in viral inactivation.

The striking finding of our study is that nanoparticles exert their antiviral effects only when added after viral
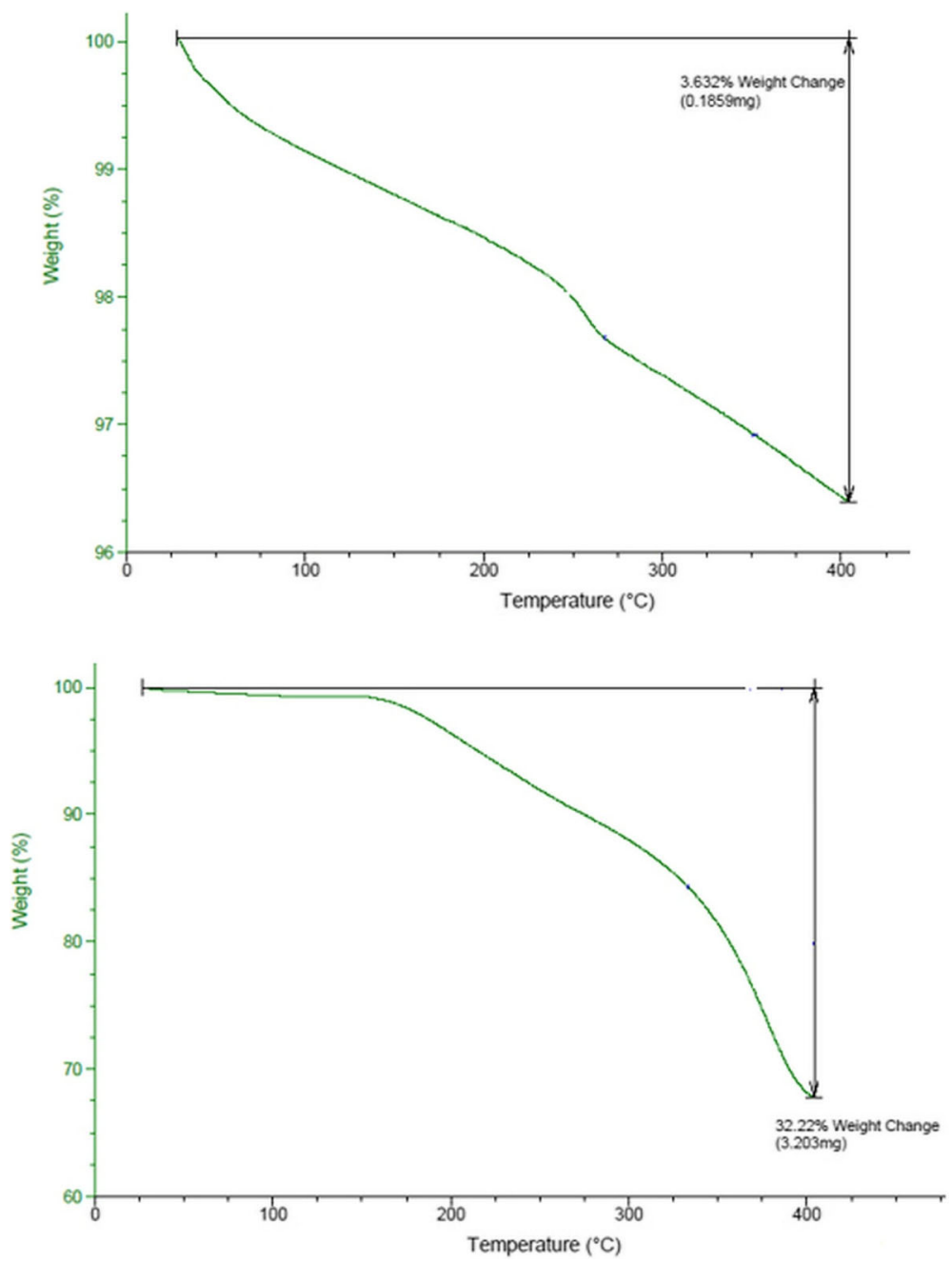

Fig. 3 Thermogravimetric analysis: a) unPEGylated ZnO-NPs; b) PEGylated ZnO-NPs 

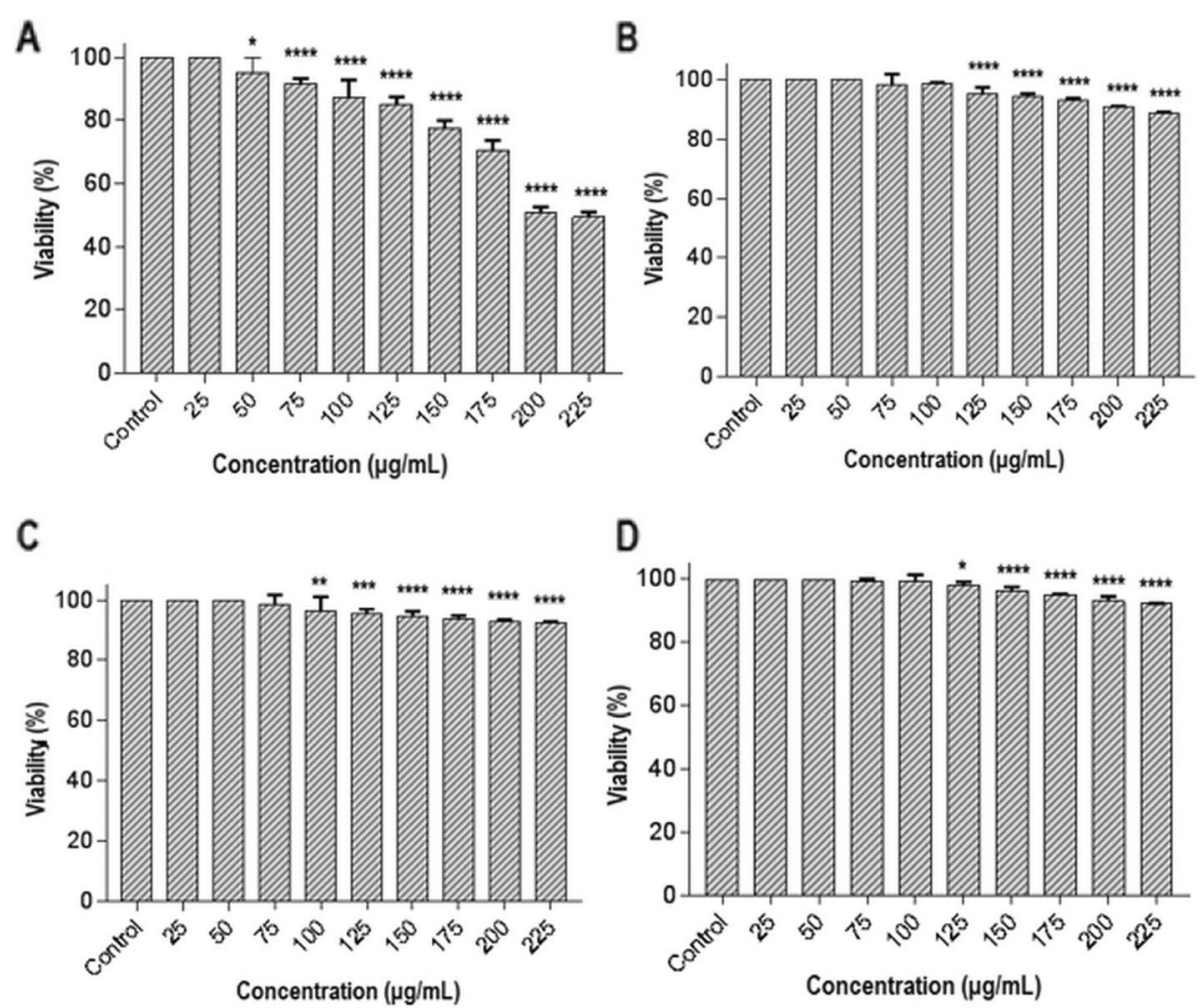

Fig. 4 Cytotoxicity of ZnO-NPs (a), ZnO-PEG-NPs (b), polyethylene glycol (c), and oseltamivir (d) on MDCK-SIAT1 cells. * Statistically significant $(p<0.05) .{ }^{*}$ Statistically significant $(p=0.003) .{ }^{* *}$ Statistically significant $(p=0.0005) .{ }^{* * *}$ Highly statistically significant $(p=0.0001)$. Error bars represent the confidence interval for the mean $(n=3)$ at the $95 \%$ level

infection of the cells, which could be resulted in a significant decrease in viral titer. Post-exposure of H1N1 influenza virus with PEGylated $\mathrm{ZnO}-\mathrm{NPs}$ at the concentrations of 75,100 , and $200 \mu \mathrm{g} / \mathrm{mL}$ could be led to 2.2, 2.4, and $2.8 \log 10$ TCID50 reduction in virus titer when compared to the virus control, respectively $(P<$ 0.0001 ), while the maximum concentration of $\mathrm{ZnO}$ NPs $(75 \mu \mathrm{g} / \mathrm{mL})$ could resulted in $1.2 \log 10$ TCID50 reduction $(P<0.0001)$. In our experiments, oseltamivir was used as a positive control for comparison of the antiinfluenza activities of the test compounds. Moreover, the polyethylene glycol at its maximal non-cytotoxic concentration $(200 \mu \mathrm{g} / \mathrm{mL})$ could resulted in $0.7 \log 10$ TCID50 reduction when compared to control $(P<0.0001)$ (Fig. 5).

The antiviral activities of $\mathrm{ZnO}-\mathrm{NPs}$ and $\mathrm{ZnO}$-PEG-NPs against H1N1 influenza virus were further confirmed by quantitative Real-Time PCR. It was observed that the antiviral activity was in a dose-dependent manner, so that the ZnO-PEG-NPs at the concentration of 25, 75, 100, and $200 \mu \mathrm{g} / \mathrm{mL}$ led to inhibition rates of $0.6,78.2,80.3$, and $94.6 \%$, respectively. The inhibition rates were calculated based on the influenza viral loads. It is obvious that the anti-influenza activity of ZnO-PEG-NPs is greater than that of $\mathrm{ZnO}-\mathrm{NPs}$. The maximum antiviral effect of $\mathrm{ZnO}$ NPs was obtained at the concentration of $75 \mu \mathrm{g} / \mathrm{mL}$ with the inhibition rate of $52.2 \%$ (Fig. 6). It is notable that the production of influenza virus was completely inhibited by oseltamivir at the concentration of $75 \mu \mathrm{g} / \mathrm{mL}$. Furthermore, the inhibition rate of soluble polyethylene glycol was $13.5 \%$ at its maximal non-cytotoxic concentration (Fig. 6).

\section{Indirect immunofluorescence assay}

To study the inhibitory impact of nanoparticles on the expression of influenza virus antigens on the MDCKSIAT1 cells surface, an indirect immunofluorescence assay (IFA) was performed. In this assay, we used the highest non-toxic concentration of ZnO-NPs and ZnO-PEG-NPs which showed the greatest antiviral effect in the previous experiments. In parallel, both negative and positive controls were also included. Figure 7 shows a substantial decrease in fluorescence emission intensity in influenzainfected cell treated with ZnO-PEG-NPs at the concentration of $200 \mu \mathrm{g} / \mathrm{mL}$ compared to the positive control, and with lower intensity in influenza-infected cell treated with $\mathrm{ZnO}-\mathrm{NPs}$ at the concentration of $75 \mu \mathrm{g} / \mathrm{mL}$.

\section{Discussion}

The H1N1 influenza virus is a significant global public health threat with the potential to cause worldwide 


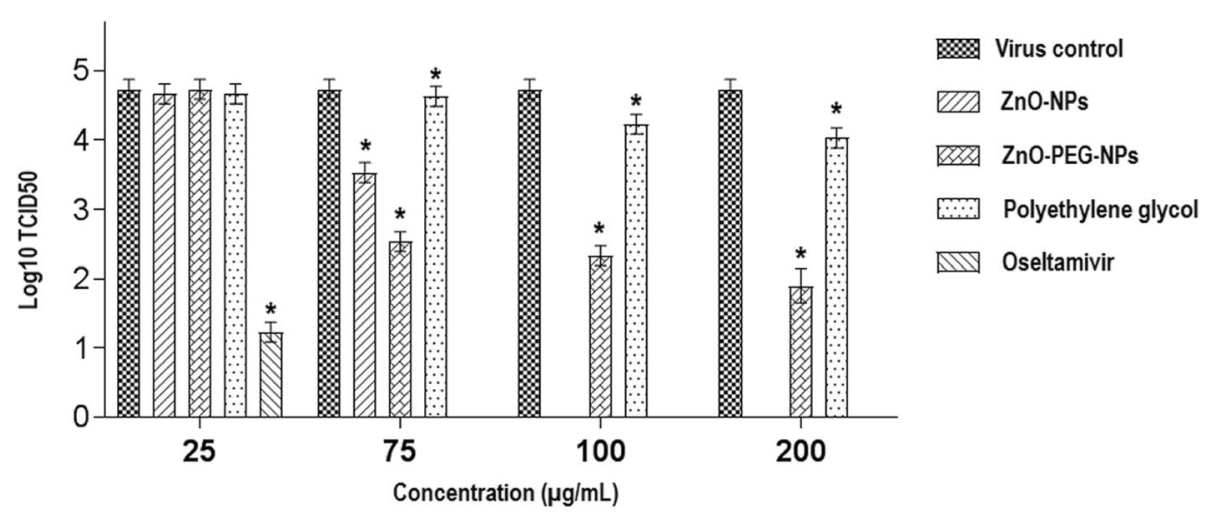

Fig. 5 Assessment of the post-exposure antiviral activity of ZnO-NPs, ZnO-PEG-NPS, polyethylene glycol, and oseltamivir on the titer of H1N1 influenza virus by TCID50 assay. ${ }^{*}$ Statistically significant $(p<0.0001)$. Error bars represent the confidence interval for the mean $(n=3)$ at the 95\% level

epidemics and pandemics. The current antiviral drugs against influenza are weakened due to their significant adverse effects and the increasing appearance of drug-resistant strains during the course of treatment [20] and so, development of new and effective anti-influenza agents is urgently required. Compared to the conventional treatments, there are several advantages to using nanoparticles for therapeutics such as effectiveness in lower concentrations, potent antiviral activity against drug-resistant viruses, cost-effective synthesis, and suitability for different coating types $[16,21]$. In the current study, we used H1N1 strain, A/Puerto Rico/8/34 (H1N1) (PR8) as the virus model, and assessed the antiviral properties of $\mathrm{ZnO}-\mathrm{NPs}$ and PEGylated $\mathrm{ZnO}-\mathrm{NPs}$ on $\mathrm{H} 1 \mathrm{~N} 1$ virus. In order to achieve to this aim, we conducted a series of in vitro cell culture-based experiments.
Our results have shown that ZnO-PEG-NPs have a stronger antiviral effect along with lower cytotoxicity compared to $\mathrm{ZnO}-\mathrm{NPs}$, confirming that surface PEGylation of nanoparticles plays a key role in enhancement of antiviral activity against H1N1 influenza virus and reduction of cell cytotoxicity on MDCK-SIAT1 cells. Such results corroborate findings from our recent research in which we demonstrated that PEGylated $\mathrm{ZnO}-\mathrm{NP}$ was associated with higher antiviral activity against herpes simplex virus type 1 (HSV-1) and lower cytotoxicity on Vero cell line [16]. In accordance with these findings, Martinez etal. Performed the MTT cell viability assay for assessment of cytotoxicity of ZnO-NPs and ZnO-PEGNPs on MCF-7 breast cancer cells, and they demonstrated the higher cytotoxicity for bare $\mathrm{ZnO}$-NPs compared to the PEGylated ZnO-NPs. In the previous studies, it has been

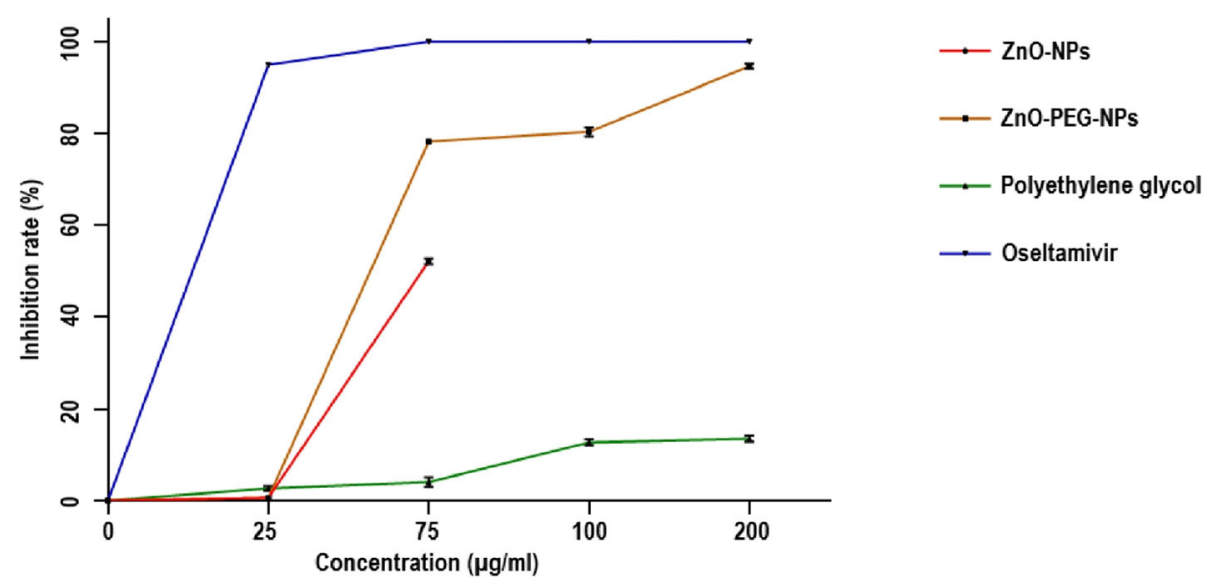

Fig. 6 The inhibitory rates of the four compounds against H1N1 influenza virus determined by Real-Time PCR assay regarding to the postexposure antiviral activity. According to the one-way ANOVA followed by Tukey's multiple comparisons test, there were significant differences among the groups $(p<0.0001)$, except for ZnO-NPs vs. ZnO-PEG-NPs at the concentration of $25 \mu \mathrm{g} / \mathrm{mL}$. Error bars represent the confidence interval for the mean $(n=3)$ at the $95 \%$ level 


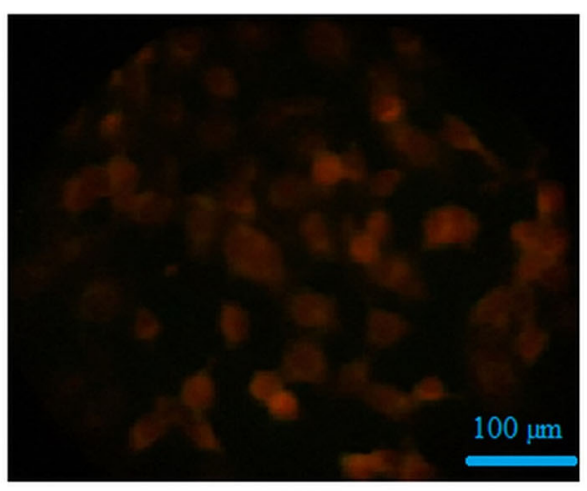

(a)

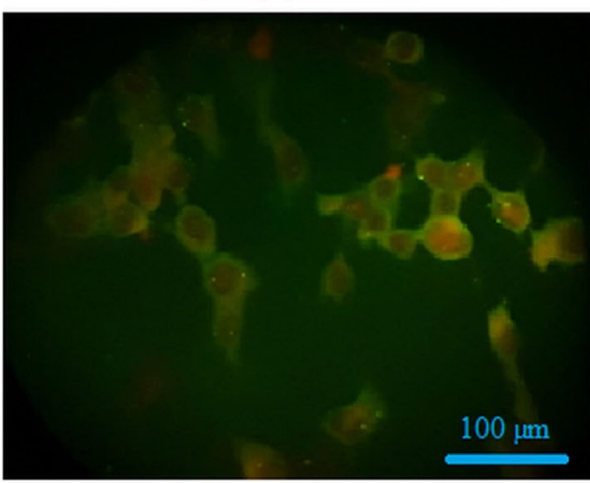

(c)

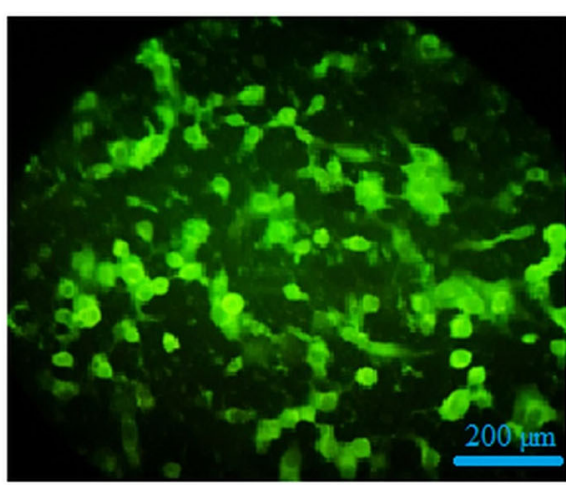

(b)

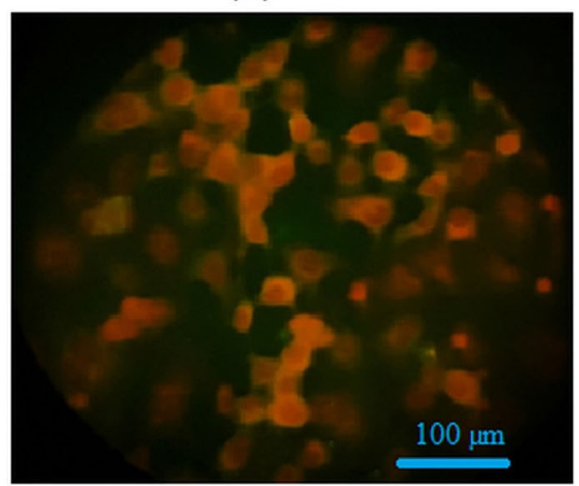

(d)

Fig. 7 Immunofluorescence staining for detection of H1N1 influenza virus antigens in the MDCK-SIAT1 cells. (a) Cell control, (b) Virus control, (c) Infected cells treated with ZnO-NPs $(75 \mu \mathrm{g} / \mathrm{ml})$ and (d) $200 \mu \mathrm{g} / \mathrm{ml} \mathrm{ZnO}-\mathrm{PEG}-\mathrm{NPs}$ at $24 \mathrm{~h}$ post infection

revealed that $\mathrm{ZnO}-\mathrm{NPs}$ produce $\mathrm{Zn}^{2}+$ ions and also, different types of reactive oxygen species (ROS) such as superoxides, hydroxyl radicals, and hydrogen peroxide which apparently damage lipids, proteins, carbohydrates and DNA, and finally lead to cell apoptosis [15]. As an explanation, it is proposed that the surface coating of $\mathrm{ZnO}$ NPs with polymeric materials such as polyethylene glycol can lead to a significantly decrease in cytotoxicity through masking of nanoparticles and subsequently, preventing the release of $\mathrm{Zn} 2+$ ions and ROS.

The results have shown that the nanoparticles have inhibitory activities to suppress the proliferation of influenza virus when added $1 \mathrm{~h}$ after infection. As shown in the results, pre- and co-exposure of cells to nanoparticles did not result in any decrease in the titer of H1N1 influenza virus. These findings indicate that the nanoparticles do not induce antiviral state on MDCK-SIAT1 cells, and also, do not occupied specific receptors involved in attachment and entry of influenza particles into the host cells. These experimental results show that the nanoparticles target and interfere with the some stages in the life cycle of the influenza virus which occur after viral adsorption and internalization by the cells.
Although, the results of antiviral assay revealed that inhibitory potential of $\mathrm{ZnO}-\mathrm{NPs}$ and $\mathrm{ZnO}-\mathrm{PEG}-\mathrm{NPs}$ against H1N1 influenza virus was only documented in post-exposure antiviral assay, antiviral activity during the pre- and co-exposure of cells to the nanoparticles cannot be completely ruled out. This possibility arises from different incubation times of nanoparticles and virus. In the post-infection setup, the nanoparticles were incubated with infected cells and viruses for $48 \mathrm{~h}$, whereas it was shorter $(\leq 1 \mathrm{~h})$ for pre- and co-treatment assays. Here, incubation time is a key factor and can dramatically influence the cellular uptake of nanoparticles.

It has been reported that due to increase in surface hydrophilicity, PEGylation leads to reduced cellular uptake of nanoparticles $[22,23]$. On the other hand, influenza viruses carry out their transcription and replication entirely inside the cell [24]. Here, the question is that how the PEGylated $\mathrm{ZnO}$ nanoparticles can exert the higher antiviral activity than the bare $\mathrm{ZnO}$ nanoparticles? This obvious discrepancy can be rationalized by the explanation that PEGylation of nanoparticles using the severe mechanical ball milling in our study led to production of smaller particle size. It should be noted 
that smaller nanoparticles are more likely to be passively internalized by cells [25].

ZnO-PEG-NPs have been shown to have higher antiviral potency than the bare $\mathrm{ZnO}-\mathrm{NPs}$ at the same concentrations. The difference can be justified by several explanations. Our findings demonstrated that soluble polyethylene glycol at its maximal non-cytotoxic concentration $(200 \mu \mathrm{g} / \mathrm{ml})$ had slightly antiviral activity on influenza virus (with inhibition rate of $13.5 \%$ ). As an explanation, the higher antiviral activity of ZnO-PEG-NPs than the bare $\mathrm{ZnO}-\mathrm{NPs}$ can be attributed to the surface PEGylation of $\mathrm{ZnO}$ nanoparticles. On the other hand, PEGylation of nanoparticles using the severe mechanical ball milling in our study resulted in production of nanostructures with smaller particle size. It should be noted that decreasing in particle size of nanoparticles leads to: (1) increased surface area to volume ratio; (2) facilitated diffusion of particles into cells; and (3) decreased agglomeration and increased rate of dissolution properties.

Over recent years, few studies have been conducted to investigate the inhibitory effects of various nanostructures on influenza virus infection. In the most recent work, Kumar et al. assessed antiviral activity of Fe3O4 nanoparticles (IO-NPs) against PR8-H1N1strain, and they proposed the IO-NPs as the potent influenza virus inhibitor with 8 fold decrease in viral RNA [26]. In another study by Lin et al., antiviral properties of selenium nanoparticles (SeNPs) and zanamivir modified selenium nanoparticles (Se@ZNV) against H1N1 influenza virus investigated, and their results indicated that Se@ZNV has a higher antiviral activity compared to the SeNPs and zanamivir alone [27]. Similarly, Li et al. conducted a study to investigate antiviral capabilities of SeNPs and oseltamivir surface-modified SeNPs (Se@OTV) against H1N1 influenza virus [28]. Their findings showed that Se@OTV is associated with higher antiviral activity and has less toxicity. Interference with influenza virus life cycle by inhibition of hemagglutinin and neuraminidase activities was suggested as a possible mechanism.

During the last stage of the influenza virus replication cycle, newly assembled viral particles should be released from the cell surface. In this step, influenza's neuraminidase enzyme cleaves the attachment between hemagglutinin on the progeny virus and sialic acid receptor on the host cell. Oseltamivir and zanamivir are sialic acid analogues and neuraminidase inhibitors which prevents this cleavage step, and interfere with the release of progeny influenza virus from infected host cells and subsequently, prevent the progression of infection $[29,30]$. Since that in the studies conducted by Lin et al. and Li et al., oseltamivir and zanamivir modified selenium nanoparticles were used for evaluation of anti-influenza activity, the possible antiviral mechanism could be inhibition of hemagglutinin and neuraminidase activities.

\section{Conclusions}

Our study was the first research which examined the inhibitory effects of $\mathrm{ZnO}-\mathrm{NPs}$ on $\mathrm{H} 1 \mathrm{~N} 1$ influenza virus. The results showed that PEGylated $\mathrm{ZnO}-\mathrm{NPs}$ have a higher anti-influenza activity along with lower cytotoxicity compared to bare $\mathrm{ZnO}-\mathrm{NPs}$, suggesting that surface PEGylation of nanoparticles can be effective in enhancement of antiviral activity against H1N1 influenza virus and reduction of cell cytotoxicity on MDCK-SIAT1 cells. Our in vitro experiments also demonstrated that the nanoparticles have inhibitory properties against influenza virus only after viral entry into the host cells. The future studies can be designed to explore the exact antiviral mechanism of the nanoparticles using more developed techniques such as transmission electron microscope (TEM), as well as to examine the pattern of influenza virus gene expression in the presence of the nanoparticles.

\section{Acknowledgements \\ This work was thesis for PhD degree in medical virology. The study was financially supported by Iran University of Medical Sciences (Grants No. 9321540003). \\ Authors' contributions \\ SHM and AAP provided administrative and material support. SHM and AAP provided the study concept and design. HG performed all experiments. AT and HG wrote the manuscript, and reviewed and edited the manuscript. HG and AT interpreted data. MF performed statistical analysis. AM, AT, ME, MZ, DJ, SJK, and FB provided critical feedback on drafts of the manuscript. VPM helped to make revisions of the manuscript and to perform cell culture experiments. All authors have read and approved the final manuscript.}

\section{Funding}

Iran University of Medical Sciences.

Availability of data and materials

Not applicable.

Ethics approval and consent to participate

Not applicable.

\section{Consent for publication}

Not applicable.

\section{Competing interests}

The authors declare that they have no competing interests.

\section{Author details}

${ }^{1}$ Department of Medical Virology, Iran University of Medical Sciences, Tehran, Iran. ${ }^{2}$ Department of Microbiology, School of Medicine, Golestan University of Medical Sciences, Gorgan, Iran. ${ }^{3}$ Cellular and Molecular Research Center, Iran University of Medical Sciences, Tehran, Iran. ${ }^{4}$ Department of Medical Nanotechnology, Faculty of Advanced Technologies in Medicine, Iran University of Medical Sciences, Tehran, Iran. ${ }^{5}$ Department of Virology, School of Public Health, Tehran University of Medical Sciences, Tehran, Iran. ${ }^{6}$ Neuroscience Research Center, Iran University of Medical Sciences, Tehran, Iran.

Received: 12 June 2019 Accepted: 3 September 2019

Published online: 10 September 2019

\section{References}

1. Tavakoli A, Rezaei F, NASAB GSF, Adjaminezhad-Fard F, Noroozbabaei Z, Mokhtari-Azad T. The comparison of sensitivity and specificity of ELISA- 
based microneutralization test with hemagglutination inhibition test to evaluate neutralizing antibody against influenza virus (H1N1). Iran J Public Health. 2017;46(12):1690.

2. World Health Organization. https://www.who.int/en/news-room/fact-sheets/ detail/influenza-(seasonal). Accessed 6 Nov 2018.

3. Keshavarz M, Tavakoli A, Mozaffari Nejad AS, Mokhtari-Azad T, Rezaei F. A review of influenza vaccination among different population groups in Iran. J Clin Diagn Res. 2018;12:6

4. Moghoofei M, Monavari SH, Mostafaei S, Hadifar S, Ghasemi A, Babaei F, et al. Prevalence of influenza a infection in the M iddle-E ast: a systematic review and meta-analysis. Clin Respir J. 2018;12(5):1787-801.

5. Chaisri U, Chaicumpa W. Evolution of therapeutic antibodies, influenza virus biology, influenza, and influenza immunotherapy. Biomed Res Int. 2018; 2018:9747549.

6. Esghaei M, Monavari SHR, Tavassoti-Kheiri M, Shamsi-Shahrabadi M, Heydarchi B, Farahmand B, et al. Expression of the influenza M2 protein in three different eukaryotic cell lines. J Virol Methods. 2012;179(1):161-5.

7. Toledo-Rueda W, Rosas-Murrieta NH, Muñoz-Medina JE, González-Bonilla CR, Reyes-Leyva J, Santos-López G. Antiviral resistance markers in influenza virus sequences in Mexico, 2000-2017. Infect Drug Resist. 2018;11:1751.

8. Ding Y, Cao Z, Cao L, Ding G, Wang Z, Xiao W. Antiviral activity of chlorogenic acid against influenza a $(\mathrm{H} 1 \mathrm{~N} 1 / \mathrm{H} 3 \mathrm{~N} 2)$ virus and its inhibition of neuraminidase. Sci Rep. 2017;7:45723.

9. Nguyen JT, Smee DF, Barnard DL, Julander JG, Gross M, de Jong MD, et al. Efficacy of combined therapy with amantadine, oseltamivir, and ribavirin in vivo against susceptible and amantadine-resistant influenza a viruses. PLoS One. 2012;7(1):e31006.

10. Tavakoli A, Hashemzadeh MS. Inhibition of herpes simplex virus type 1 by copper oxide nanoparticles. J Virol Methods. 2019; https://doi.org/10.1016/j. jviromet.2019.113688.

11. Mackie A, Gourcy S, Rigby N, Moffat J, Capron I, Bajka B. The fate of cellulose nanocrystal stabilised emulsions after simulated gastrointestinal digestion and exposure to intestinal mucosa. Nanoscale. 2019;11(6):2991-8.

12. Mukherjee S, Patra CR. Biologically synthesized metal nanoparticles: recent advancement and future perspectives in cancer theranostics. Future Sci OA. 2017;3(3):FSO203.

13. Jain N, Bhargava A, Rathi M, Dilip RV, Panwar J. Removal of protein capping enhances the antibacterial efficiency of biosynthesized silver nanoparticles. PLoS One. 2015;10(7):e0134337.

14. Brandelli A, Ritter AC, Veras FF. Antimicrobial activities of metal nanoparticles. Metal nanoparticles in pharma: Springer; 2017. p. 337-63.

15. Siddiqi KS, ur Rahman A, Husen A. Properties of zinc oxide nanoparticles and their activity against microbes. Nanoscale Res Lett. 2018;13(1):141.

16. Tavakoli A, Ataei-Pirkooh A, Mm Sadeghi G, Bokharaei-Salim F, Sahrapour P, Kiani SJ, et al. Polyethylene glycol-coated zinc oxide nanoparticle: an efficient nanoweapon to fight against herpes simplex virus type 1. Nanomedicine. 2018;13(21):2675-90.

17. Reed $\amalg$, Muench $H$. A simple method of estimating fifty per cent endpoints. Am J Epidemiol. 1938;27(3):493-7.

18. Zhou J, Zhao F, Wang Y, Zhang Y, Yang L. Size-controlled synthesis of ZnO nanoparticles and their photoluminescence properties. J Lumin. 2007;122: $195-7$.

19. Khoshhesab ZM, Sarfaraz M, Asadabad MA. Preparation of ZnO nanostructures by chemical precipitation method. SYNTH REACT INORG M. 2011:41(7):814-9.

20. Makau JN, Watanabe K, Mohammed MM, Nishida N. Antiviral activity of peanut (Arachis hypogaea L.) skin extract against human influenza viruses. J Med Food. 2018;21(8):777-84.

21. Monavari SH. The inhibitory effect of acyclovir loaded nano-niosomes against herpes simplex virus type-1 in cell culture. Med J Islam Repub Iran. 2014;28:99.

22. Soenen SJ, Manshian BB, Abdelmonem AM, Montenegro JM, Tan S, Balcaen $L$, et al. The cellular interactions of PEGylated gold nanoparticles: effect of PEGylation on cellular uptake and cytotoxicity. Part Part Syst Charact. 2014. 31(7):794-800

23. Shen TW, Fromen CA, Kai MP, Luft JC, Rahhal TB, Robbins GR, et al. Distribution and cellular uptake of PEGylated polymeric particles in the lung towards cell-specific targeted delivery. Pharm Res. 2015;32(10):3248-60.

24. Akarsu H, Iwatsuki-Horimoto K, Noda T, Kawakami E, Katsura H, Baudin F, et al. Structure-based design of NS2 mutants for attenuated influenza a virus vaccines. Virus Res. 2011;155(1):240-8.
25. Rosa S, Connolly C, Schettino G, Butterworth KT, Prise KM. Biological mechanisms of gold nanoparticle radiosensitization. Cancer Nanotechnol. 2017;8(1):2.

26. Kumar R, Nayak M, Sahoo GC, Pandey K, Sarkar MC, Ansari Y, et al. Iron oxide nanoparticles based antiviral activity of H1N1 influenza a virus. J Infect Chemother. 2019;25(5):325-9.

27. Lin Z, Li Y, Guo M, Xiao M, Wang C, Zhao M, et al. Inhibition of H1N1 influenza virus by selenium nanoparticles loaded with zanamivir through p38 and JNK signaling pathways. RSC Adv. 2017;7(56):35290-6.

28. Li Y, Lin Z, Guo M, Xia Y, Zhao M, Wang C, et al. Inhibitory activity of selenium nanoparticles functionalized with oseltamivir on H1N1 influenza virus. Int J Nanomedicine. 2017;12:5733

29. Mittal N, Medhi B. The bird flu: a new emerging pandemic threat and its pharmacological intervention. Int J Health Sci. 2007;1(2):277.

30. Webster D, Li Y, Bastien N, Garceau R, Hatchette TF. Oseltamivir-resistant pandemic H1N1 influenza. CMAJ. 2011;183(7):E420-E2.

\section{Publisher's Note}

Springer Nature remains neutral with regard to jurisdictional claims in published maps and institutional affiliations.

Ready to submit your research? Choose BMC and benefit from:

- fast, convenient online submission

- thorough peer review by experienced researchers in your field

- rapid publication on acceptance

- support for research data, including large and complex data types

- gold Open Access which fosters wider collaboration and increased citations

- maximum visibility for your research: over $100 \mathrm{M}$ website views per year

At $\mathrm{BMC}$, research is always in progress.

Learn more biomedcentral.com/submissions 